\title{
Üst Gastrointestinal Sistem Kanamaları: Son 5 Yılda Başvuran 68 Hastanın Retrospektif Analizi
}

\author{
Orhan ÇiMEN ${ }^{1 *}$, Ferda KESKİ ÇiMEN²ْ
}

1. Erzincan Binali Yıldırım Üniversitesi Tıp Fakültesi Genel Cerrahi Anabilim Dalı

2. Erzincan Binali Yıldırım Üniversitesi Tıp Fakültesi Patoloji Anabilim Dalı

Geliş / Received: 04/03/2020, Kabul / Accepted: 18/03/2020

\section{$\ddot{O} \mathbf{z}$}

Giriş ve Amaç: Üst gastrointestinal kanama, üst özefagus sfinkteri ile Treitz ligamenti arasında kalan üst gastrointestinal kanal içerisinde gercekleşen kanamadır, proksimal duodenum kanamaları da bu grupta yer almaktadır. Materyal ve Metot: Son beş yıldır hastanemize üst gastrointestinal kanama nedeni ile başvuran hastalara uygulanan tetkik ve tedavi kayıtları incelendi. Hastalara ait yaş,cinsiyet,geliş hemogram sonuçları,üst gastrointestinal sistem endoskopi sonuçları, uygulanan endoskopik girişimler,tekrar endoskopi ihtiyaçları,hastaların kan ve kan ürünü ihtiyaçları, altta yatan etyolojik faktörler, endoskopi esnasında biyopsi alınıp alınamadığı, alınabildi ise patoloji sonuçları, Helicobacterpylori varlığı ve/veya yokluğu, Helicobacterpylori var olan hastalarda şiddeti kayıt altına alındı. Bulgular: Çalışmamızda 25 ( \%36,8) kadın, $43(\% 63,2)$ erkek hastanın üst gastrointestinal kanama nedeni ile başvurduğu gözlemlendi. Çalışmamızda yer alan hastaların yaş aralığının 12-101 olduğu görüldü. 6 hastaya $(\% 8,8)$ kanama durdurmaya yönelik adrenalin enjeksiyonu,1 hastaya (\% 1,4) adrenalin enjeksiyonu ile birlikte koterizasyon yapıldı. 61 hastada $(\% 89,8)$ kanama endoskopik bir girişime gerek kalmadan kendiliğinden durmuş idi. Hiçbir hastaya cerrahi girişim ihtiyacı olmadı. Tartışma ve Sonuç: Çalışmamız neticesinde elde edilen birçok verinin literatürde yapılan çalşmalar ile benzer olduğu görüldü.Ancak çalışmaya dahil edilen hastalara cerrahi müdahale gerekmemesi ve mortalite görülmeyişi anlamlı olarak bulundu.Bunun nedeninin hastanemize erken başvuru oranının yüksek oluşu, ileri düzey endoskopik girişimlerin hastanemizde yapılabiliyor oluşu, çalışmaya dahil edilen hasta sayısının literatürdeki çalışmalar ile kıyaslandığında daha az sayıda olması gibi nedenlerden kaynaklandığı kanısı taşımaktayız.

Anahtar Kelimeler: üst gastrointestinal kanama, Helicobacter pylori, peptik ülser

\section{Upper Gastrointestinal Bleeding: Retrospective Analysis of 68 Patients Presenting in the Last 5 Years}

\begin{abstract}
Background and Aim: Upper gastrointestinal bleeding is the bleeding that occurs in the upper gastrointestinal tract between the upper esophageal sphincter and the Treitz ligament, and proximal duodenal bleeding is also included in this group. Material and Method: The examination and treatment records of patients who have been admitted to our hospital for the last five years due to upper gastrointestinal bleeding were examined. Age, gender, arrival hemogram results, upper gastrointestinal system endoscopy results, applied endoscopic interventions, repeat endoscopy needs, blood and blood product needs of patients, underlying etiological factors, presence of biocopsy during endoscopy, presence of pathology, Helicobacterpylori and / or severity was recorded in patients with Helicobacterpylori. Results: In our study, 25 (36.8\%) female and 43 (63.2\%) male patients were observed to apply for upper gastrointestinal bleeding. The age range of the patients in our study was found to be $12-101.6$ patients $(8.8 \%)$ had adrenaline injection aimed at stopping bleeding, and 1 patient $(1.4 \%)$ received cauterization with adrenaline injection. Bleeding stopped spontaneously in 61 patients
\end{abstract}

Sorumlu Yazar: ssenocak@orhancimen24@hotmail.com 
(89.8\%) without the need for an endoscopic intervention. No patient needed surgical intervention. Discussion and Conclusion: It was found that many data obtained as a result of our study were similar to the studies in the literature. However, the patients included in the study were found not to require surgical intervention and mortality. We believe that the number of patients included in the study was due to fewer numbers compared to studies in the literature.

Keywords: Upper gastrointestinal bleeding, Helicobacter pylori, peptik ülser

\section{Giriş}

Üst gastrointestinal kanama, üstözefagus sfinkteri ile Treitz ligamenti arasında kalan üst gastrointestinal kanal içerisinde gercekleşen kanamadır, proksimal duodenum kanamaları da bu grupta yer almaktadır (Okutur vd., 2007)). Subklinik sinsi bir kanamadan akut hipovolemik şoka sebebiyet verecek kadar masif kanamaya kadar değișen klinik tablolar halinde gözlemlenebilir (Yamada 2002). 103/100000 oranında görülmektedir. Tüm hastaneye yatış nedenlerinin $\%$ 1 kadarının sebebi üst sindirim kanalı kanamalarıdır (Ulaşoğlu 2002). Özefagus varis kanaması nedeni ile gelişenler hariç, $\% 80$ gibi yüksek oranda spontan durma söz konusudur (Pfau vd., 2004, Ericksonn vd., 1986). Gerek medikal, gerekse invaziv yöntemlerde görülen bütün gelişmelere rağmen mortalite oranı halen $\% 10$ gibi yüksek oranlara çıkmaktadır.Mortaliteyi etkileyen faktörler arasında yaş,kanamanın nüks kanama oluşu,hastanın sahip olduğu ek hastalıklar, daha önce geçirilen ameliyatlar,hematemez ile sağlık kuruluşuna başvuru, başvuru esnasinda hipotansiyon bulunması, peptik ülser ve özefagus varisleri nedeni ile kanamanın gerçekleşmiş olması başlıca sayılabilir (Mungan 2001). Üst gastrointestinal kanama nedeni ile başvuran hastaların yarıya yakınında kanama nedeni olarak peptik ülser olarak tespit edilmiştir. Yaşlı hastalar başta olmak üzere \%30'a varan oranlarda neden olarak NSAIII kullanım öyküsü tespit edilmiștir (Hernandez-Diaz vd., 2000).

Çalışmamızda hastanemize son beș yıldır, üst gastrointestinal kanama sebebi ile başvuran 68 hastaya ait tetkik ve tedavi kayıtları retrospektif olarak incelenerek, üst gis endoskopi sonuçları, yaş, cinsiyet, geliş hemoglobin değerleri, kan ve kan ürünü ihtiyaçları, kanamayı durdurmaya yönelik yapılan endoskopik girişimler, patoloji sonuçları, H.pylori varlığı ve şiddeti, biyopsi alınıp alınamadığı incelendi.

\section{Materyal ve Metot}

Son beș yıldır hastanemize üst gastrointestinal kanama nedeni ile başvuran hastalara uygulanan tetkik ve tedavi kayıtları incelendi. Hastalara ait yaş, cinsiyet, geliş hemogram sonuçları, üst gastrointestinal sistem endoskopi sonuçları, uygulanan endoskopik girişimler, tekrar endoskopi ihtiyaçları, hastaların kan ve kan ürünü ihtiyaçları, altta yatan etyolojik faktörler, endoskopi esnasında biyopsi alınıp alınamadığı, alınabildi ise patoloji sonuçları, Helicobacter pylori varlığı ve/veya yokluğu, Helicobacter pylori var olan hastalarda şiddeti kayıt altına alındı.

İlk endoskopi olarak hastaya başvuru anından itibaren ilk 24 saat içerisinde yapılan endoskopi, tekrar endoskopi ihtiyacı olarak 24 saat sonra kanaması devam eden hastalara tekrarlanmak zorunda kalınan kontrol endoskopisi tanımland. Geliş hemogram değeri ise hastanın başvuru esnasında 
çalışılan hemogram değeri olarak tanımlandı. Helicobacter pylori şiddeti olarak patoloji raporlarında yer alan Helicobacter pylori pozitiflik derecesi kullanıldi $(+/++/+++)$. İhtiyaç duyulan kan ve kan ürünleri ünite bazında değerlendirildi.

İstatistik yöntemi olarak, Yüzde Oranı kullanılarak daha sade ve anlaşılabilir sonuçlar elde edilmeye çalışıldı.

$\mathrm{Bu}$ çalışma, Erzincan Binali Yıldırım Üniversitesi, Klinik Araştırmalar Etik Kurul Başkanlığı tarafından onaylanmıştır. (Karar No:03/03, Say1:33216249-903.99-E.13848)

\section{Bulgular}

Çalışmamızda 25 ( \%36,8) kadın, 43 (\%63,2) erkek hastanın üst gastrointestinal kanama nedeni ile başvurduğu gözlemlendi.

Çalışmamızda yer alan hastaların yaş aralığının 12-101 arasında olduğu görüldü. Yaş ortalaması ise 62,8 olarak tespit edildi.

Hastaların tümüne endoskopi uygulanmıştı. Ancak 4 hastaya $(\% 5,8)$ tekrar kanama nedeni ile tekrar endoskopisi uyguland. Tekrar endoskopide kanama durdurucu işlem uyguland. 6 hastaya $(\% 8,8)$ kanama durdurmaya yönelik adrenalin enjeksiyonu,1 hastaya (\% 1,4 ) adrenalin enjeksiyonu ile birlikte koterizasyon yapıldı. 61 hastada $(\% 89,8)$ kanama endoskopik bir girişime gerek kalmadan kendiliğinden durmuş idi. Hiçbir hastaya cerrahi girişim ihtiyacı olmadi.

Hastaların \%20,5'inde kan ve kan ürünü transfüzyon ihtiyacı doğmuş olduğu görüldü. Sadece 1 hastaya 10 ünite eritrosit suspansiyonu, 4 ünite taze donmuş plazma olmak üzere masif transfüzyon yapıldığ 1 gözlemlendi. Kan ve kan ürünü transfüzyonu uygulanan 14 hastadan 4'ünün üst gastrointestinal endoskopi sonucunun mide malign neoplazmı, 3'ünün bulbus ülseri, 2 'sinin antrum ülseri, 1 'inin fundus ülseri, 1'inin mide polibi, 1'inin gastrit, 1'inin özefagus varis kanaması ile uyumlu olduğu, 1 'inin kanama sebebinin görülemediği tespit edildi.

21 hastanın $(\% 30,8)$ üst gastrointestinal endoskopi sonucunun gastrit, 19 hastanın $(\% 27,9)$ bulbus ülseri, 9 hastanın $(\% 13,2)$ gastrik ülser, 6 hastanın $(\% 8,8)$ mide neoplazmı, 4 hastanın (\% 5,8) özefajit, 1 hastanın $(\% 1,4)$ özofagus varisi ,1 hastanın $(\% 1,4)$ mide polibi ile uyumlu olduğu gözlemlenirken, 7 hastada (\% 11,7) kanama nedeni ile suboptimal olarak raporlandığ ve kanama nedeninin belirlenemediği görüldü.

22 hastadan (\% 32,3) kanama nedeni ile biyopsi alınamadığı görüldü. Gerek ilk, gerkese tekrar endoskopilerinde biyopsi alınan 46 hastanın patoloji raporlarının 26'sinın $(\% 56,2)$ gastrit, 8'inin $(\% 17,3)$ intestinal metaplazi, 6'sinın $(\% 13,1)$ mide malign neoplazm1, 1 'inin $(\% 2,1)$ hiperplastik polip, 1'inin $(\% 2,1)$ özefajit ile uyumlu olduğu, $4(\% 8,6)$ hastada ise yetersiz numune olarak raporlandığı fark edildi.

24 hastanın patoloji raporunda Helicobacter pylori pozitifliği tespit edildi. 10 hastada bir pozitif, 11 hastada 2 pozitif, 3 hastada üç pozitif Helicobacter pylori mevcut idi. 24 hastadan 13'ünün endoskopi sonucu gastrit, 6'sının endoskopi sonucu bulbus ülseri, 3 'ünün endoskopi sonucu gastrik ülser, 2'sinin endoskopi sonucu özefajit ile uyumlu idi. Bulbus ülseri ile birlikte görülen Helicobacter pozitiflik şiddet dağılımı incelendiğinde 4 hastanın 2 pozitif, 1 hastanın 3 pozitif, 1 hastanın 1 pozitif şeklinde olduğu gözlemlendi. 
Geliş hemogram tetkiklerine göre hemoglobin değeri 10' unun altında olan hasta sayısının 17, hemoglobin değeri $10^{6}$ un üzerinde hasta sayısının 51 olduğu görüldü. Geliş hemoglobin değeri 10'un altında olan 17 hastanın 4'ünde bulbusta ülser, 5 hastada ise mide malign neoplazmı ve 8 hastada ise gastrit olduğu üst gastrintestinal sistem endoskopisi sirasında tespit edildi.

\section{Sonuç ve Tartışma}

Treitz ligamentinin proksimalinde görülen kanamalar olarak da tarif edilen üst gastrointestinal sistem kanamaları nadir olmayan acil problemlerden olup,sindirim sistemi kanalından köken alan kanamaların \%80’nini oluştururlar (Günsar vd., 1997). Üst gastrointestinal sistem kanama nedenleri sıralaması, çeşitli çalışmalarda değişkenlik arz etmektedir. Bu nedenlerin birçoğunda ilk sırayı peptik ülser, ikinci sırayı eroziv gastrit, üçüncü sırayı özefagus varis kanamaları almıştır (Bilgin vd., 1991). Çalışmamız üst gastrointestinal kanama nedenleri sıklığı açısından literatür ile uyumlu çıkmış olup ilk sırayı peptik ülser, ikinci sırayı ise eroziv gastrit almıştır. Kanama sıklığına göre yaş dağılımı yapıldığında literatürde en sık kanamanın 30-60 yaş grubunda görüldüğü gözlemlenmiştir (Tiellman, 2015). Bizim çalışmamızda kanama sıklığının 40-80 yaş grubunda daha sık olduğu görüldü. Literatür ile uyumlu olarak çalışmamızda da kanamanın özellikle 60 yaş ve üzeri grupta daha sık görüldüğü tespit edildi. Bu tespit üst gastrointestinal sistem kanamalarında 60 yaş ve üzeri yaş grubunda olmanın önemli bir risk faktörü olduğunu bir kez daha ortaya konmuş oldu (Göral vd., 1994).

Erkeklerde üst gastrointestinal kanamanın daha s1k görülmesinin etmenlerinden biri olarak erkeklerde komorbit hastalıkların daha sık görülmesi de gösterilmektedir. Ayrıca gastrik mukoza dayanıklık ve bütünlüğünün kadınlarda daha iyi olduğu da ikinci bir iddiadır (Shenmak 1995). Bizim çalışmamızda da literatür ile uyumlu olarak, üst gastrointestinal kanamaların erkek cinsiyette daha sık görülmekte olduğu $\% 63,2$ oranı ile teyit edilmiş oldu.

Üst gastrointestinal kanamalı olguların \% 80'inde kanama herhangi bir müdahaleye gerek kalmadan spontan olarak sona ermekte ve başka komplikasyon ortaya çıkmamaktadır. Geriye kalan \%20'lik grupta ise süregelen kanamaların yol açtığı çeşitli kanamalar gözlemlenmektedir. Süregelen kanamalar neticesinde \%25 ila \%40 arasinda değişen oranlarda mortalite gerçekleşmektedir. \%10-30 oranında cerrahi müdahale kaçınılmaz olmaktadır (Rotondano, 2014) . Çalışmamızda ise 61 hastada $(\% 89,8)$ kanama endoskopik bir girişime gerek kalmadan kendiliğinden durmuş idi. Hiçbir hastaya cerrahi girişim ihtiyacı olmadı. Hiç mortalite gözlemlenmedi.

Ülkemizde Helicobacter pylori enfeksiyonu yüksek oranda mevcuttur. Yapılan bir çalışmada duodenal ülserli olgularda Helicobacter pylori pozitiflik oranı \%16.1, mide ülserli olgularda ise $\% 9.2$ oranında bulundu (Özen vd., 2007). Bizim çalışmamızda ise 24 hastamızda $(\% 35,2)$ Helicobacter pylori pozitifliği mevcuttu. 24 hastadan 13'ünün endoskopi sonucu gastrit, 6'sinın endoskopi sonucu bulbus ülseri, 3'ünün endoskopi sonucu gastrik ülser, 2 'sinin endoskopi sonucu özefajit ile uyumlu idi.

Çalışmamız neticesinde elde edilen birçok verinin geçmişte yapılan çalışmalar ile benzer olduğu görüldü. Ancak çalışmaya 
dahil edilen hastalara cerrahi müdahale gerekmemesi ve hiç mortalite görülmeyişi anlamlı olarak bulundu. Bunun nedeninin hastanemize erken başvuru oranının yüksek oluşu, ileri düzey endoskopik girişimlerin hastanemizde yapılabiliyor oluşu, çalışmaya dahil edilen hasta sayısının geçmiş çalışmalar ile kıyaslandığında daha az sayıda hasta içermesi gibi nedenlerden kaynaklandığ kanısı taşımaktayız.

Etik Kurul Onayı: Bu çalışma, Erzincan Binali Yıldırım Üniversitesi, Klinik Araştırmalar Etik Kurul Başkanlığ tarafından onaylanmıştır. (Karar No:03/03, Say1:33216249-903.99-E.13848)

\section{Kaynaklar}

Bilgin, A., Karaayvaz, M., Doğru, O., Kama, NA. 1991. 'Üst gastrointestinal sistem kanamaları (38 vakanın incelenmesi)", Gastroentereloji. $4: 704-7$

Erickson, R.A., Glick, M.E. 1986. 'Why have controlled trials failed to demonstrate a benefit of esophagogastroduodenoscopy in acute upper gastrointestinal bleeding? A probability model analysis" Dig Dis Sci. 31: 760-8.

Göral, V., Doğan, Y., Kart, S., Yükselen, V., Değertekin, H., Canoruç, F. 1994. 'Üst Gastrointestinal sistem kanamaları (69 vakanın incelenmesi)", Gastroenteroloji. 2:238-41.

Hernandez-Diaz, S., Garcia Rodriguez, LA. 2000 "Association between nonsteroidal anti-inflammatory drugs and upper gastrointestinal tract bleeding/perforation: an overview of epidemiologic studies published in the 1990s"' Arch Intern Med. 160: 2093-9.

Lanas, A., Dumonceau, J.M. 2018. " Nonvariceal upper gastrointestinal bleeding", Nature Reviews Disease Primers. 18020.
Mungan, Z. 2001 'Üst gastrointestinal sistem kanamalar1' Gastroenterohepatoloji. Nobel T>p Kitabevleri, İstanbul. 75.

Okutur, SK. 2007. ' Akut üst gastrointestinal sistem kanamaları: 230 olgunun analizi" Akademik Gastroenteroloji Dergisi. 6 (1): 30-36.

Özen, E., Tekin, F., Oruç, N. 2007. ' 'Varis dış1 üst gastrointestinal sistem kanamalı 412 olgunun irdelenmesi", Akademik Gastroenteroloji Dergisi. 6 (2): 62-67.

Pfau, PR., Cooper, GS., Carlson, MD. 2004. "Success and shortcomings of a clinical care pathway in the management of acute nonvariceal upper gastrointestinal bleeding, Am J Gastroenterol. 99: 425-31.

Rotondano, G. 2014. ''Epidemiology and diagnosis of acute nonvariceal upper gastrointestinal bleeding'. Gastroenterol. Clin. North Am. 43: 643-663.

Shennak, MM. 1995. ''Etiology of upper gastrointestinal bleeding in,Jordanian patients: A prospective study' Ann Saudi Med. 15:1-12

Tielleman, T., Bujanda, D., Cryer, B. 2015. 'Epidemiology and risk factors for upper gastrointestinal bleeding" Gastrointest. Endosc. Clin. N. Am. 25: 415-428.

Ulaşoğlu, C. 2002. 'Varis d〉ş〉 üst gastrointestinal sistem kanamaları" Çapa Gastroenteroloji Günleri Mezuniyet Sonrası Ĕ̈itim Kursu Kitabı. 28.

Yamada, T. 2002. 'Handbook of Gastroenterology", Lippincott Williams \& Wilkins. Philadelphia, 16-8. 